University of Nebraska - Lincoln

DigitalCommons@University of Nebraska - Lincoln

USDA Wildlife Services - Staff Publications

U.S. Department of Agriculture: Animal and Plant Health Inspection Service

$10-1-2021$

\title{
Threading the needle: How humans influence predator-prey spatiotemporal interactions in a multiple-predator system
}

\author{
Asia Murphy \\ Pennsylvania State University, aum432@psu.edu \\ Duane R. Diefenbach \\ US Geological Survey \\ Mark Ternent \\ Pennsylvania Game Commission \\ Matt Lovallo \\ Pennsylvania Game Commission \\ David Miller \\ Pennsylvania State University \\ Follow this and additional works at: https://digitalcommons.unl.edu/icwdm_usdanwrc \\ Part of the Natural Resources and Conservation Commons, Natural Resources Management and \\ Policy Commons, Other Environmental Sciences Commons, Other Veterinary Medicine Commons, \\ Population Biology Commons, Terrestrial and Aquatic Ecology Commons, Veterinary Infectious Diseases \\ Commons, Veterinary Microbiology and Immunobiology Commons, Veterinary Preventive Medicine, \\ Epidemiology, and Public Health Commons, and the Zoology Commons
}

Murphy, Asia; Diefenbach, Duane R.; Ternent, Mark; Lovallo, Matt; and Miller, David, "Threading the needle: How humans influence predator-prey spatiotemporal interactions in a multiple-predator system" (2021). USDA Wildlife Services - Staff Publications. 2518.

https://digitalcommons.unl.edu/icwdm_usdanwrc/2518

This Article is brought to you for free and open access by the U.S. Department of Agriculture: Animal and Plant Health Inspection Service at DigitalCommons@University of Nebraska - Lincoln. It has been accepted for inclusion in USDA Wildlife Services - Staff Publications by an authorized administrator of DigitalCommons@University of Nebraska - Lincoln. 


\title{
Threading the needle: How humans influence predator-prey spatiotemporal interactions in a multiple-predator system
}

\author{
Asia Murphy $^{1}$ (D) | Duane R. Diefenbach ${ }^{2}$ | Mark Ternent $^{3}$ | Matt Lovallo ${ }^{3}$ | \\ David Miller ${ }^{4}$ (D)
}

${ }^{1}$ Intercollege Graduate Degree Program in Ecology, Pennsylvania State University, University Park, PA, USA

${ }^{2}$ U.S. Geological Survey, Pennsylvania Cooperative Fish and Wildlife Research Unit, Pennsylvania State University, University Park, PA, USA

${ }^{3}$ Pennsylvania Game Commission, Harrisburg, PA, USA

${ }^{4}$ Department of Ecosystem Science and Management, Pennsylvania State University, University Park, PA, USA

\section{Correspondence \\ Asia Murphy \\ Email: aum432@psu.edu}

Funding information

Pennsylvania Game Commission; PNC

Financial Corporation; Pennsylvania State

University; PNC Financial Corporation

Graduate Fellowship; Penn State Alumni

Association Graduate Fellowship; Penn State

Bunton-Waller Graduate Award

Handling Editor: Laura Prugh

\section{Abstract}

1. Perceived predation risk and the resulting antipredator behaviour varies across space, time and predator identity. Communities with multiple predators that interact and differ in their use of space, time of activity and hunting mode create a complex landscape for prey to avoid predation. Anthropogenic presence and disturbance have the potential to shift interactions among predators and prey and the where and when encounters occur.

2. We examined how white-tailed deer Odocoileus virginianus fawn spatiotemporal antipredator behaviour differed along an anthropogenic disturbance gradient that had black bears Ursus americanus, coyotes Canis latrans, bobcats Lynx rufus and humans present.

3. We quantified (a) spatial co-occurrence in species distributions, (b) temporal overlap across the diel cycle and (c) spatiotemporal associations between humans, bears, coyotes, bobcats, adult male deer and fawns. We also examined how deer vigilance behaviour changed across the anthropogenic disturbance gradient and survey duration.

4. Anthropogenic disturbance influenced spatiotemporal co-occurrence across multiple scales, often increasing spatiotemporal overlap among species. In general, species' spatial co-occurrence was neutral or positive in anthropogenically disturbed environments. Bears and fawns, coyotes and adult male deer, and bobcats and fawns all had higher temporal overlap in the agriculture-development matrix sites. In addition, factors that influenced deer vigilance (e.g. distance to forest edge and predator relative abundance) in the agriculture-development matrix sites did not in the forest matrix site.

5. By taking into account the different antipredator behaviours that can be detected and the different scales these behaviours might occur, we were able to gain a more comprehensive picture of how humans reduce available niche space for wildlife, creating the neutral and positive spatiotemporal associations between species that studies have been seeing in more disturbed areas.

KEYWORDS

anthropogenic disturbance, multiple predators, predation risk, predator-prey interactions, risk allocation, spatiotemporal co-occurrence, vigilance 


\section{1 | INTRODUCTION}

Predator-prey interactions and the resulting antipredator behaviours are crucial to organizing community structure. Anthropogenic disturbance and human Homo sapiens presence can greatly influence predator-prey interactions, as humans are perceived as predators by species across trophic levels (Nickel et al., 2020; Suraci et al., 2019). If only predators perceive humans as dangerous, then their spatiotemporal avoidance of humans might create refuges for prey (Berger, 2007). However, if predators and prey perceive humans as dangerous, then predator spatiotemporal avoidance of humans (Frid \& Dill, 2002) might further constrain prey, leaving prey with the challenge of spatiotemporally avoiding natural predators within an ever-shrinking available spatiotemporal space. If prey are unable to spatiotemporally avoid natural predators, the only recourse left is increasing vigilance, group sizes and other predation risk diffusion behaviours, which might lead to increased stress and decreased recruitment and survival (Cherry et al., 2016). In the end, extirpation from the habitat might result (Shamoon et al., 2018). Studies that do not include humans as an effect while attempting to characterize how prey perceive predation risk might misinterpret how prey navigate landscapes of fear (Dorresteijn et al., 2015).

The white-tailed deer Odocoileus virginianus (hereafter, 'deer') is an economically and ecologically influential ungulate that inhabits a wide range of habitat types (Quinn et al., 2013). The primary cause of mortality in deer fawns (hereafter, 'fawns') across their range is predation (Gingery et al., 2018), and because the species has a large geographic range, fawns are often susceptible to predation by a number of interacting predators across a gradient of anthropogenic disturbance, making it an ideal species in which to examine how interacting predators and anthropogenic disturbance influences antipredator behaviour. Our goal was to examine how human-dominated landscapes influenced (a) spatiotemporal interactions between humans, black bears
Ursus americanus (hereafter, 'bears'), coyotes Canis latrans, bobcats Lynx rufus, fawns, and (b) deer vigilance behaviour. We used camera trap data from six surveys in and around three public forest sites (782-1,072 km²; Table 1; Figure 1) with different surrounding matrix types (e.g. forest and agriculture and development) and proximity to anthropogenic disturbance (i.e. distance to forest edge). We examined predator-predator spatiotemporal interactions because interactions between predators and the spatiotemporal use of multiple predators (association or avoidance) can influence interactions with shared prey (Embar et al., 2014; Polis \& Holt, 1992; Wilken et al., 2014). We also examined adult ( $\geq 1$ year old) male deer spatiotemporal co-occurrence and vigilance with humans and three predators as a 'control', because adult male deer are rarely depredated by these predators unless injured or sick (Wallingford et al., 2017). We assume the adult male deer do not perceive humans as threats during our data collection period, despite their hunting season occurring shortly afterward in October, as studies have shown that hunted species are cognizant of precisely when humans are expected to be a threat (Little et al., 2016; Tolon et al., 2009).

\section{1 | Hypotheses}

For predation to occur, predators and prey must overlap in space and time (Guiden et al., 2019). Because the likelihood of predators and prey overlapping often depends on foraging/hunting style (Breviglieri et al., 2013), prey (e.g. fawns) should spatially avoid ambush predators (e.g. bobcats), which tend to localize their hunting efforts in areas that provide them higher rates of predation success (Valeix et al., 2009). Meanwhile, prey should avoid roaming predators (e.g. coyotes and bears), which actively search for prey across an area (Bastille-Rousseau et al., 2016), by decreasing their temporal overlap (Schmitz et al., 2017). Because bears and coyotes tend to be active at different times (Bridges et al., 2004; Chamberlain

TABLE 1 Summary of survey effort and mean values of anthropogenic disturbance indicators for six camera trap surveys at and around three Pennsylvanian public forests (Bald Eagle-BE; Rothrock-RO; Susquehannock-SU) in 2016 and 2017. Bald Eagle and Rothrock were surrounded by agriculture and development, while Susquehannock was surrounded by forest

\begin{tabular}{|c|c|c|c|c|c|c|c|c|}
\hline \multirow[b]{2}{*}{ Site } & \multirow[b]{2}{*}{ \# of trap nights ${ }^{\mathrm{b}}$ (dates) } & \multirow[b]{2}{*}{$\begin{array}{l}\text { \# of camera } \\
\text { locations }\end{array}$} & \multicolumn{6}{|c|}{ Mean values of anthropogenic disturbance indicators $(S D)^{a}$} \\
\hline & & & Matrix & disted $(\mathrm{km})$ & $\begin{array}{l}\text { distdev } \\
(\mathrm{km})\end{array}$ & $\operatorname{dev}(\%)$ & esf (\%) & ag (\%) \\
\hline \multirow[t]{2}{*}{ BE } & $2,077(7 / 26-9 / 13 / 16)$ & 47 & $A D$ & $2.3(1.1)$ & $2.4(1.1)$ & $0.2(6.2)$ & $0.0(2.0)$ & $5.8(30.9)$ \\
\hline & $1,492(6 / 17-9 / 4 / 17)$ & 43 & & & & & & \\
\hline RO & $2,079(5 / 23-7 / 25 / 16)$ & 50 & $A D$ & $1.9(1.0)$ & $1.8(0.9)$ & $3.8(25.5)$ & $10.7(35.0)$ & $9.8(38.6)$ \\
\hline \multirow[t]{2}{*}{ SU } & $3,956(5 / 25-9 / 6 / 16)$ & 57 & $\mathrm{~F}$ & $2.8(1.2)$ & $2.3(0.9)$ & $0.4(8.0)$ & $44.6(46.9)$ & $5.2(27.1)$ \\
\hline & $3,550(6 / 12-9 / 12 / 17)$ & 57 & & & & & & \\
\hline Overall & 16,013 & 330 & & $2.3(0.7)$ & $2.2(0.7)$ & $1.5(15.3)$ & $18.4(51.1)$ & $7.0(16.9)$ \\
\hline
\end{tabular}

${ }^{a}$ Matrix-type of habitat surrounding the public forest lands, AD (agriculture-development) and F (forest); disted-distance from camera location to nearest forest edge $(\mathrm{km})$; distdev-distance from camera location to nearest development $(\mathrm{km})$; dev-percentage of habitat $1 \mathrm{~km}$ around camera location that is development; esf-percentage of habitat $1 \mathrm{~km}$ around camera location that is early successional forest/shrubland; ag-percentage of habitat $1 \mathrm{~km}$ around camera location that is agriculture.

${ }^{\text {b}}$ Trap nights defined as the number of 24 -hr periods a camera was operational. 


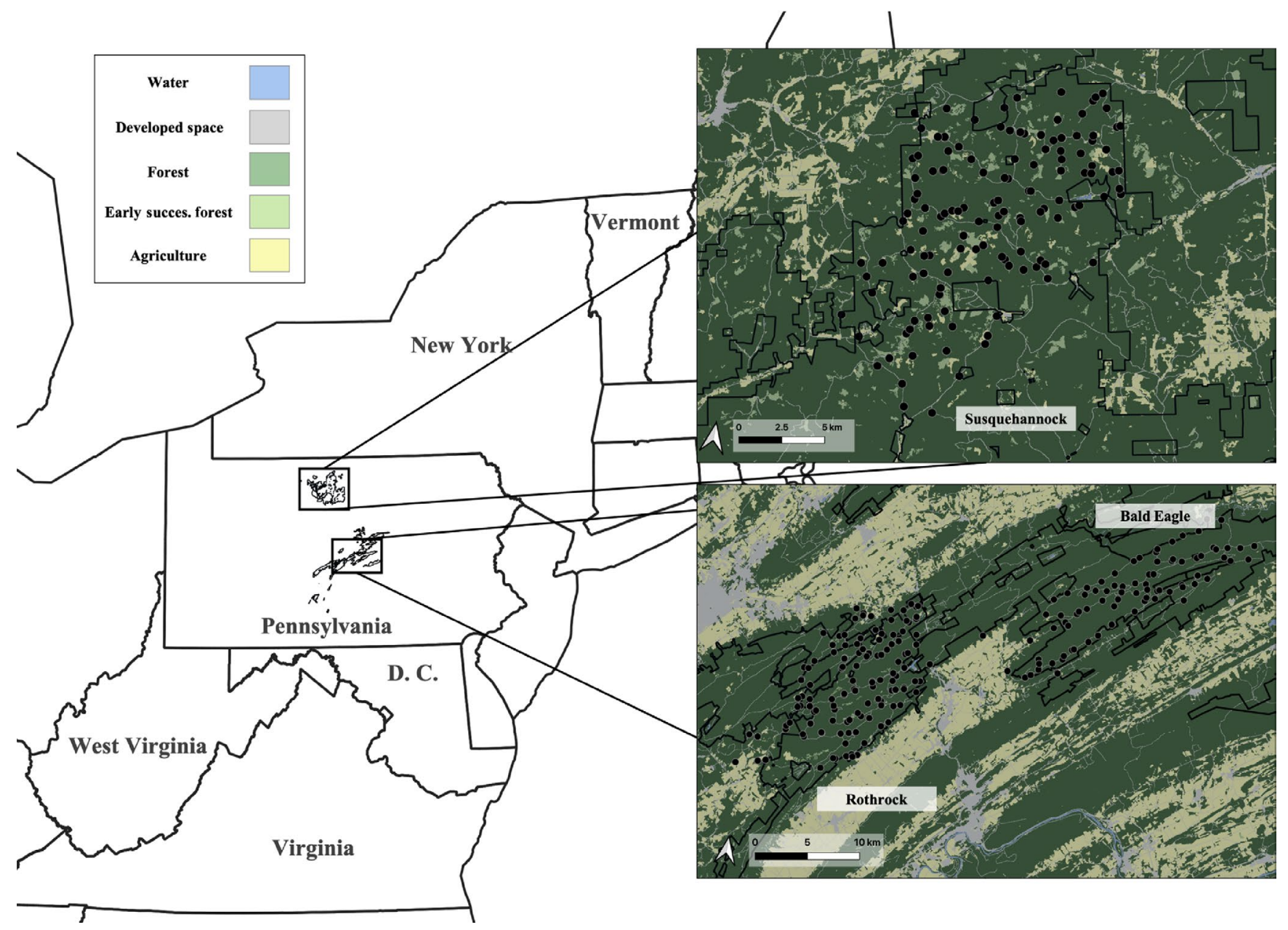

FIGURE 1 Map of the three study sites: Bald Eagle, Rothrock, and Susquehannock State Forests. Camera trap surveys occurred in each study site between May and September (2016-2017). The two southern study sites (Bald Eagle and Rothrock) are largely surrounded by human development and private land (proportion of land cover that is agriculture/developed habitat within $10 \mathrm{~km}$ : 0.21 ) while the land surrounding the northern study site (Susquehannock) is largely forested and public (proportion of land cover that is agriculture/developed habitat within $10 \mathrm{~km}$ : 0.07). Black lines are state forest boundaries and black circles are locations where camera traps were placed

et al., 1998; Way et al., 2004), fawns are left with few predator-free hours. This might cause fawns to instead swap complete temporal avoidance for another form of antipredator behaviour: increased vigilance during times when bears and coyotes are active. Finally, the likelihood of a kill, even with spatiotemporal overlap, depends on the prey's individual vulnerability, which can change (e.g. young ungulates becoming harder to catch as they grow older; Rayl et al., 2018). Because fawns become harder to catch as they grow older, fawn spatiotemporal avoidance of all three predators might lessen as the summer continues.

Humans and anthropogenic disturbance complicate this already complicated network of interspecific interactions. All three predators show some degree of spatiotemporal avoidance of humans (Nickel et al., 2020; Smith et al., 2018; Stillfried et al., 2015; Wang et al., 2015), despite bobcats being the most intolerant of anthropogenic disturbance (Wang et al., 2015). This suggests that in our more anthropogenically disturbed sites, spatiotemporal space might be reduced, increasing spatiotemporal overlap between species and increasing the importance of vigilance for fawns. Because human use of state forests is localized to certain areas (e.g. trails), like an ambush predator, we would expect all species to spatially avoid humans on the landscape. We developed a matrix of predictions about how fawns, adult male deer, bears, bobcats and coyotes would interact with each other and humans based on surrounding matrix type, species and interaction type (Table 2, Appendices S1 and S2).

\section{2 | MATERIALS AND METHODS}

\section{1 | Study areas and camera-trapping surveys}

We collected detection/non-detection data by surveying bears, coyotes, bobcats and deer in and around three Pennsylvanian public forests sites (Bald Eagle, Rothrock and Susquehannock) in 2016 and 2017 using camera traps (IACUC \#47057; Table 1; Figure 1). Bald Eagle (BE) and Rothrock (RO) were surrounded by agriculture and low-density 


\begin{tabular}{|c|c|}
\hline Mechanism $^{a}$ & Prediction ${ }^{b}$ \\
\hline \multirow[t]{3}{*}{ Space } & Wildlife will show independent spatial co-occurrence with humans \\
\hline & $\begin{array}{l}\text { Forest matrix site spatial co-occurrence between wildlife will be independent; } \\
\text { in the agriculture-development matrix sites, wildlife will positively co-occur }\end{array}$ \\
\hline & $\begin{array}{l}\text { Fawns will spatially avoid bobcats earlier in the summer; later, bobcats and } \\
\text { fawns will show independent and positive spatial co-occurrence in the forest } \\
\text { and the agriculture-development matrix sites respectively }\end{array}$ \\
\hline \multirow[t]{2}{*}{ Time } & $\begin{array}{l}\text { Human-wildlife temporal overlap will be lower-and wildlife-wildlife temporal } \\
\text { overlap higher-in the agriculture-development matrix sites }\end{array}$ \\
\hline & Fawn temporal overlap with other species will be higher later in the summer \\
\hline \multirow[t]{4}{*}{ Space-Time } & $\begin{array}{l}\text { Human-wildlife and wildlife-wildlife spatiotemporal associations will be } \\
\text { neutral in the forest matrix site and negative in the agriculture-development } \\
\text { matrix sites }\end{array}$ \\
\hline & Coyote-bobcat and bobcat-deer spatiotemporal associations will be negative \\
\hline & Natural predators will have positive spatiotemporal associations with fawns \\
\hline & $\begin{array}{l}\text { Early summer fawn spatiotemporal associations with humans, coyotes, and } \\
\text { bears will be negative; late summer associations will only be negative in the } \\
\text { agriculture-development matrix sites }\end{array}$ \\
\hline \multirow[t]{4}{*}{ Vigilance } & Deer vigilance will increase with anthropogenic disturbance \\
\hline & $\begin{array}{l}\text { Deer vigilance will be higher at the times of day when predators were most } \\
\text { active }\end{array}$ \\
\hline & $\begin{array}{l}\text { Fawns and adult females with fawns will be more vigilant with increased } \\
\text { predator relative abundance }\end{array}$ \\
\hline & $\begin{array}{l}\text { The vigilance of adult females with fawns and fawns will decrease throughout } \\
\text { the summer }\end{array}$ \\
\hline
\end{tabular}

${ }^{\text {a }}$ Spatial and temporal co-occurrence is measured across all camera locations using multispecies occupancy models and kernel density estimation. Spatiotemporal co-occurrence is measured across all camera locations, with data collapsed temporally at 12-hr and 1-day scales. Changes between early summer and late summer were measured by comparing spatial, temporal and spatiotemporal co-occurrence using data from early summer (pre-July 26th; $n=64$ and 65 days in 2016 and 2017, respectively) and late summer (July 26th and onward; 50 and 49 days in 2016 and 2017, respectively).

${ }^{b}$ Independent (or neutral) co-occurrence-two species co-occur together at rates equal to what would be expected at random; attraction (or positive)-two species co-occur together at rates that are more than what would be expected at random; avoidance (or negative)-two species co-occur together at rates that are less than what would be expected at random.
TABLE 2 Predictions on how spatiotemporal co-occurrence between humans and wildlife, and deer vigilance, would change over matrix types, survey duration, space, time and space-time housing, whereas Susquehannock (SU) was surrounded by largely contiguous forest (Table 1). Camera trap surveys began in mid- to late May, which coincided with the start of when fawns are born and most vulnerable to predation (Gingery et al., 2018; Vreeland et al., 2004), and ended in mid-September, before the hunting season. We plotted random locations spaced a minimum of $1 \mathrm{~km}$ apart within a $240-\mathrm{km}^{2}$ area encompassing each site and cameras were placed as close to the plotted location as was feasible given accessibility. Eighteen camera locations were placed on private land bordering BE and RO in 2017 (Table 1). At least one camera (Covert Scouting Cameras MP8 Black; Covert Scouting Cameras) was placed at each location and typically remained there for an average of 47 days (range: 12-104 days) before being moved to a new location. Cameras were set to take three pictures when triggered with a 1-min rest period.

We define a 'detection event' as the moment an individual(s) triggers the camera, resulting in a number of pictures of the individual(s), the duration of which starts with the first trigger and ends within $30 \mathrm{~min}$. Because all our cameras were placed randomly (i.e. not on a trail or other highly used paths), we baited locations with a combination of bobcat urine, a skunk-based scent attractant (Caven's Gusto and Minnesota Brand Bobcat Urine; Minnesota Trapline Products), and a fatty acid tablet (USDA Wildlife Services). Bait was refreshed approximately every 10-14 days. Because preliminary analyses show that the mean number of times a location was baited had no appreciable effect on detection, we assumed bait did not influence animal space use at the scale we were measuring responses and that animals detected came from the general vicinity of the camera location. It is likely that our overall rates of deer vigilance are higher than might have been if we had not baited (Eccard et al., 2017); however, this should be consistent across sites, so the relationships we see between deer vigilance and covariates are not influenced. Because the distance between camera locations was less than the diameter of all species' home ranges, one individual could be detected at multiple locations; we use 'occurrence' to denote species use of a camera location. Human detections included motorists and people on foot. 


\section{2 | Covariates}

We chose covariates that we felt might influence species space use based on previous analyses conducted on species' habitat use using the same data (Murphy, 2021) and removed highly correlated variables $(|r|>0.70)$. In addition to use matrix type (e.g. agriculture-development or forest; mat) as a categorical variable, we estimated the percent developed space (dev), early successional forest-shrubland (esf) and agriculture (ag) within a 1-km radius for each camera location from the 2016 National Land Cover Database (USGS, 2019). Esf incorporated shrubland and deciduous, coniferous and mixed forests with canopy height of $<5 \mathrm{~m}$. Ag included pasture and cropland, and dev included developed open space and developed space of low, medium and high intensities (USGS, 2019). We measured the distance of each camera location to the nearest forest edge outside of the public forest boundary (disted) and the nearest cell of developed space (distdev; km) using ArcGIS (ESRI, Redlands, CA). RO had the lowest mean disted $(1.87 \pm S E 0.09 \mathrm{~km})$ and distdev $(1.72 \pm S E 0.08 \mathrm{~km})$ values of all three sites and $S U$ had the highest disted values $(2.75 \pm S E 0.11 \mathrm{~km})$. Mean ag and dev values were similar among all sites but $B E$ had the lowest esf estimate $(0.02 \pm S E 0.21)$ and SU had the highest (44.57 \pm SE 4.39).

A categorical covariate for 'summer period' (sum) was created to investigate how fawn spatiotemporal co-occurrence changed over the summer. The sum value depended on whether the camera location was being surveyed before July 26 (early summer when fawns are more vulnerable to predation; 0) or after (late summer; 1). Fawn detections were more inconsistent before July 26 (0.91 \pm SD 0.29 detections per day) compared to after $(0.98 \pm S D 0.14$ detections per day), suggesting either lower numbers of fawns available or more circumspect behavior due to their vulnerability.

\section{3 | Spatial co-occurrence}

We fit single-season multispecies occupancy models (Rota et al., 2016) in package unmarked (v. 0.13-2; Fiske \& Chandler, 2011) in R (v. 3.6.1; R Core Team, 2020) to characterize spatial cooccurrence among humans, adult male deer, fawns and the three predators. Data from both years were analysed together as independent locations with identical habitat information if the locations were within $100 \mathrm{~m}$ of each other. We determined how relative cooccurrence probabilities changed with respect to mat, disted, distdev, dev, esf, ag and sum. We assembled capture histories where each of our focal species was either detected (1) or undetected (0) at a camera location during a survey occasion (i.e. eight contiguous trap nights; 17 total survey occasions). Human detections included all humans except researchers. We developed two sets of models, one with humans, predators and fawns to examine predator-prey interactions (hereafter, 'fawn model set') and a second with humans, predators and adult male deer, which are rarely killed by the predators studied here, as a control (hereafter, 'adult male deer set'). First, we determined what covariates influenced each species' occurrence while assuming species independence (i.e. no interactions). Once we determined the best model that explained each species' occurrence, we tested for interactions between species pairs and whether covariates influenced those interactions. We included a covariate of whether the camera was located on a trail (1) or not (0) on species' detection. We used AIC to rank models, with $\triangle \mathrm{AIC} \leq 2.0$ indicating that a model was competing (Burnham \& Anderson, 2002), and evaluated the fit of the best model by assessing model convergence and examining beta estimates and standard errors.

\section{4 | Temporal co-occurrence}

To investigate temporal co-occurrence between species, we estimated temporal overlap among species pairs using the packages activity (Rowcliffe, 2021) and overlap (Linkie \& Ridout, 2009) in R. We transformed clock times for each detection event to radians while taking into account changes in day length using average sunrise and sunset times in activity (Rowcliffe, 2021; Vazquez et al., 2019). We estimated the overlap coefficient $(\widehat{\Delta})$ for each species pair; the overlap coefficient estimates the proportion of the area where two activity curves intersect and overlap, with zero representing no overlap and one representing complete overlap (Linkie \& Ridout, 2009). We used 10,000 bootstrapped samples to estimate the $95 \%$ confidence interval $(\mathrm{Cl})$ for each overlap estimate and tested whether the overlap arose by chance using the compareCkern function in activity (Rowcliffe, 2021). We estimated temporal overlap for fawns and adult male deer with humans and the three predators during early and late summer for both matrix types.

\section{5 | Spatiotemporal co-occurrence}

To investigate spatiotemporal co-occurrence between species and investigate how they changed depending on matrix type and summer period, we used a modified directional version of Karanth et al. (2017)'s multi-response permutation procedures (Appendix S3). We estimated how the detection of one species (i.e. bear) at a camera location influenced the likelihood of detecting another species (i.e. fawn) at the same location in the following $12 \mathrm{hr}$ and 1 day after the first species was seen. While these time frames are arbitrary, they are shorter than our survey occasions (8 days each), so would provide more information than could be estimated via multispecies occupancy models. The probability of detecting the second species within the given time interval was represented by the percent of observations of the second species that occurred within the time frame. We then compared the observed probability of detecting the second species within the time frames to a null distribution of detections based on a randomization test. A larger than expected probability of observing the second species shows 'attraction' to the first species while a smaller than expected probability suggests that the second species 'avoids' the first. We failed to detect avoidance or 
attraction if the expected distribution's and observed distribution's 95\% Cls overlapped.

\section{6 | Vigilance analyses}

We examined how deer vigilance was affected by anthropogenic disturbance and predator presence by scoring deer body posture. For body posture scoring, we removed detections with (a) adult males, adult females and fawns in the same event (to avoid sexually based intraspecific effects; Lashley et al., 2014), (b) less than three pictures of a deer (to increase sample size per detection event), (c) video (as we were counting frames) and (d) detections from the preliminary survey period where locations were surveyed by two cameras simultaneously (to avoid introducing non-random selection of pictures to score). We grouped the remaining deer detections by whether they had (1) adult males, (2) adult females, (3) adult females with fawns and (4) fawns with no adult females. For each of these categories, we randomly selected a subset of detections to score; when multiple individuals were present, we scored the first animal seen. We scored each individual picture as 0 , indicating non-vigilance (i.e. eyes at or below shoulder level), or 1 , indicating either head up (i.e. eyes above shoulder level) or vigilant (i.e. eyes and chin above shoulder level) posture (Schuttler et al., 2017). When we observed adult females with fawns, we scored the adult female and the first observed fawn. We excluded photos if we could not see the head and neck of the individual in a frame, and photos that occurred after the individual that was being scored obviously noticed the camera (i.e. sniffing or looking directly at the camera; Schuttler et al., 2017). We combined data from fawns with and without adult females when analysing fawn data.

We used a generalized additive mixed model assuming a binomial distribution. Models were fit with the package mgcv (Wood, 2011) in $\mathrm{R}$. We included a random effect for individual detection events (i.e. the sequence of scored pictures taken for a single detection at a camera station; detection event), which incorporated the variation in deer vigilance that might be influenced by spatial and temporal characteristics, such as bait wear. We split our data into two datasets for training and testing the accuracy of the models. Using the training dataset, we created a biological null model, where sex-age class (type) and the number of unique individuals present (group) during the detection had an additive effect on the vigilance probability (Olson et al., 2019; Schuttler et al., 2017). We then created 11 additional models that built upon the null and varied in the covariates included, and whether the matrix type (mat) and type was included as additive effects, interactive effects on each covariate, or additive and interactive effects on each covariate (Table 3). Other than type and group, covariates were radian time (radtime), relative predator abundance (predts), disted and the day of the survey (day; see Table 3 for covariate descriptions). We used radtime with a cyclic cube regression spline as the time immediately before and after midnight

TAB LE 3 Twelve alternative parameterizations of the logistic generalized additive mixed model used to examine the factors that influenced deer vigilance probability. Covariates were selected to investigate the effect of predator presence and anthropogenic disturbance on deer vigilance. To account for multiple observations of an individual during a single camera visit, we included individual detection event as a random effect for all models

$\begin{array}{rlll}\begin{array}{l}\text { Model } \\ \text { type }\end{array} & & \text { Model formula } & \\ \text { Null } & \sim \text { type }+s(\text { group })+s(\text { detection event }) & \text { Model } \\ & \sim \text { matrix }+ \text { type }+s(\text { group })+s(\text { detection event }) & \text { name }\end{array}$

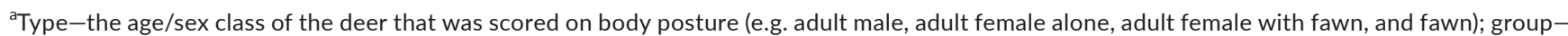
the total number of distinct individuals seen during the detection event; detection event-a factor assigning binary data to a unique detection event; matrix-the type of habitat (e.g. forest or agriculture-development) surrounding the public forest sites; radtime-the average-anchored radian time value for the detection event; predts-relative predator abundance, which is estimated by dividing the total number of black bears, coyotes, and bobcats detected at a camera location by the total number of 24-hr periods that the camera location was surveyed; disted-the distance from the camera location to the nearest forest edge (km); day-the day (i.e. Day 10) of the survey that the detection event occurred; the first day (i.e. Day 1 ) was the earliest survey day of 2016 and 2017 . Matrix*type is equivalent to 'matrix + type + matrix*type'. 
were assumed to be similar in effect. We predicted values from the training models based on the test dataset and plotted each model's ROC to assess each model's true and false positive hit rate; we chose the best model based on $\triangle \mathrm{AIC}$, the estimated area under the curve, and a visual assessment of how well the model estimated parameters (i.e. no unrealistic beta estimates and standard errors).

We predicted that adult females with fawns would have the highest vigilance probability, and that group and predts would be negatively and positively related to vigilance, respectively. Because coyotes and fawns both used forest edges, but only in the agriculture-development matrix sites (Murphy, 2021), we predicted that disted would be negatively related to vigilance in the agriculturedevelopment matrix sites. We predicted that adult females with fawns would be less vigilant later in the summer as fawns became less vulnerable to predation, but that adult male vigilance would remain the same. Finally, we predicted that deer would be more vigilant during dawn, dusk and night, as two of the three predators (e.g. coyotes and bobcats) are crepuscular and nocturnal.

\section{RESULTS}

We detected deer most frequently (6,874 observations; $96.4 \%$ of surveyed locations) and bobcats least (176 observations; $33.9 \%$ of

\begin{tabular}{|c|c|c|c|c|}
\hline \multicolumn{5}{|c|}{ Species A } \\
\hline Human & Bear & Coyote & Bobcat & $\begin{array}{c}\text { Adult male } \\
\text { deer }\end{array}$ \\
\hline $\mathrm{F} \quad \mathrm{A}$ & $\mathrm{A}$ & $\mathrm{F} \quad \mathrm{A}$ & $\mathrm{F}$ & $\begin{array}{ll}\mathrm{F} & \mathrm{A} \\
\end{array}$ \\
\hline
\end{tabular}

\begin{tabular}{l|l|l|l|l}
\hline Species B & & & & \\
\hline Bear & & & & \\
\hline Coyote & & & & \\
\hline Bobcat & & & & \\
\hline Adult male & & & & \\
Deer & & & & \\
\hline
\end{tabular}

\begin{tabular}{l|l|l|l|l}
\hline \multicolumn{5}{c|}{ Temporal overlap } \\
\hline Bear & & & & \\
\hline Coyote & & & & \\
\hline Bobcat & & & & \\
\hline Adult male & & & & \\
Deer & & & & \\
\hline
\end{tabular}

\begin{tabular}{l|l|l|l|l}
\hline \multicolumn{4}{c|}{12 Hour spatiotemporal overlap } \\
\hline Bear & & & & \\
\hline Coyote & & & & \\
\hline Bobcat & & & & \\
\hline Adult male & & & & \\
Deer & & & & \\
\hline
\end{tabular}

Deer Daily spatiotemporal overlap

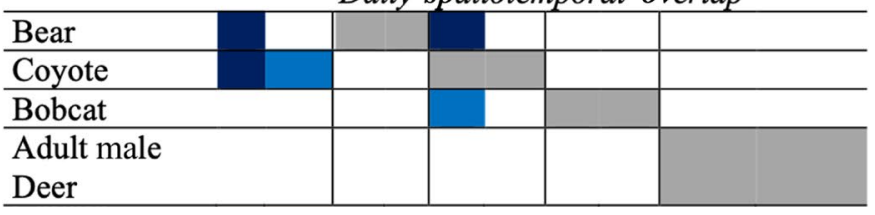

surveyed locations). Bears were detected 483 times (57.6\% of surveyed locations), coyotes 299 (38.8\% of surveyed locations) and humans 1,117 ( $13.9 \%$ of surveyed locations). Among deer detections, approximately $25 \%$ contained an adult male deer $(78.5 \%$ of surveyed locations) and $11 \%$ contained a fawn ( $47 \%$ of surveyed locations).

\section{1 | Spatial co-occurrence}

While a majority of spatial associations between species were neutral (Figure 2a,b; for model table and estimates, please see Appendices S4-S5), adult male deer, fawns and coyotes were influenced by human spatial distribution. Humans and adult male deer co-occurred together more often than could be expected at random in the agriculture-development matrix sites $(\beta=1.35 \pm S E 0.67)$ but less often in the forest matrix site $(\beta=-0.47 \pm$ SE 0.19). Humans and coyotes also co-occurred more often together than would be expected at random across all locations ( $\beta=1.12 \pm$ SE 0.50), but only in the adult male deer model set. Bears and coyotes $(\beta=1.35 \pm$ SE 0.51), bears and bobcats ( $\beta=1.51 \pm S E 0.64$ ), and bears and adult male deer ( $\beta=0.94 \pm S E 0.49$ ) co-occurred more often together than would be expected at random. Humans and fawns were positively associated closer to development in the agriculture-development matrix sites, while in the forest matrix site, this relationship was

(b)

\begin{tabular}{|c|c|c|c|c|c|}
\hline & \multicolumn{4}{|c|}{ Species A } \\
\hline & & Human & \multirow{2}{*}{\begin{tabular}{|l|} 
Bear \\
E L
\end{tabular}} & Coyote & Bobcat \\
\hline Overlap & & E L & & E L & E L \\
\hline \multirow{2}{*}{\multicolumn{6}{|c|}{ Spatial }} \\
\hline & & & & & \\
\hline \multirow{2}{*}{ Temporal } & $F$ & & & & \\
\hline & $\mathrm{A}$ & & & & \\
\hline \multirow{2}{*}{12 Hour spatiotemporal } & $\mathrm{F}$ & & & & \\
\hline & $\mathrm{A}$ & & & & \\
\hline \multirow{2}{*}{ Daily spatiotemporal } & $\mathrm{F}$ & & & & \\
\hline & $\mathrm{A}$ & & & & \\
\hline
\end{tabular}

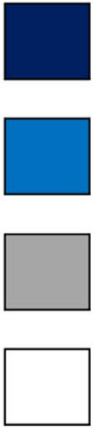

Positive

Negative

Not tested

Neutral

FIGURE 2 Spatial, temporal, and spatiotemporal co-occurrence between humans, bears, coyotes, bobcats, adult male deer, and fawns (b only) and how it changes between matrix types-forest $(F)$ and agriculture-development $(A)$-and summer period-early $(E)$ and late ( $L$ ) summer. Positive and negative values indicate beta estimates and confidence intervals did not overlap 0 
flipped (Figure 3a); coyotes and fawns also had a non-neutral spatial association which depended on matrix type (Figure $3 b$ ).

Despite the top models for coyote-fawn and bobcat-fawn spatial co-occurrence including an effect of summer period, the effect tended to be weak. The $85 \% \mathrm{Cls}$ of the probabilities of fawns occurring at camera locations with coyotes or bobcats earlier ( $\psi_{\text {coyote }}=$ $0.65 \pm S E 0.10$ and $\psi_{\text {bobcat }}=0.43 \pm S E 0.14$, respectively) and later in the summer $\left(\psi_{\text {coyote }}=0.71 \pm S E 0.10\right.$ and $\left.\psi_{\text {bobcat }}=0.65 \pm S E 0.14\right)$ overlapped.

\section{2 | Temporal co-occurrence}

Four species showed changes in temporal overlap between matrix types (i.e. 95\% Cls did not overlap; Figure 2a,b and Appendix S6). Bears and fawns $\left(\widehat{\Delta}_{\text {forest }}=0.73\right.$ vs. $\left.\widehat{\Delta}_{\text {agdev }}=0.86\right)$, coyotes and adult male deer $\left(\widehat{\Delta}_{\text {forest }}=0.59\right.$ vs. $\left.\widehat{\Delta}_{\text {agdev }}=0.82\right)$, and bobcats and fawns $\left(\widehat{\Delta}_{\text {forest }}=0.59\right.$ vs. $\left.\widehat{\Delta}_{\text {agdev }}=0.77\right)$ all had higher temporal overlap in the agriculture-development matrix sites (Figure 4). Humans and adult male deer, however, decreased in temporal overlap $\left(\widehat{\Delta}_{\text {forest }}=0.50\right.$ vs. $\widehat{\Delta}_{\text {agdev }}=0.41$; Figure 4) in the agriculture-development matrix sites.

Coyote-fawn temporal overlap increased as the summer went on, but only in the agriculture-development matrix sites $\left(\widehat{\Delta}_{\text {early_summer }}\right.$ $=0.46$ vs. $\widehat{\Delta}_{\text {late_summer }}=0.74$; Figure 5).

\section{3 | Spatiotemporal co-occurrence}

The spatiotemporal associations between species pairs were largely positive in the forest matrix site and neutral in the agriculturedevelopment matrix sites (Figure 2a,b and Appendix S7). Bears and coyotes were detected more often than would be expected at random within a day of a human detection, but only in the forest matrix site. In the agriculture-development matrix sites, coyotes were detected less often than would be expected at random within 1 day of a human detection. Bobcats were detected less often than would be expected at random within $12 \mathrm{hr}$ of a coyote detection in the forest matrix site.

Out of all the predators, only bears showed attraction to locations where fawns had been, being detected more often than would be expected at random within a day of a fawn detection in agriculture-development matrix sites. Fawns were detected less often than would be expected at random within $12 \mathrm{hr}$ of a bobcat detection, but only in the forest matrix site.

As the summer went on, fawn spatiotemporal avoidance of the three predators tended to increase, rather than decrease. In the forest matrix site, fawns went from a neutral spatiotemporal association in early summer to being detected less often than would be expected at random within $12 \mathrm{hr}$ of a human detection in late summer. Fawns in the forest matrix site were detected less often than would be expected within $12 \mathrm{hr}$ of a bobcat detection all summer, but increased avoidance to being detected less often at the day scale during late summer. In the forest matrix sites, fawn detections were lower than would be expected at random within 1 day of a coyote detection, but only later in the summer. In contrast, in the agriculture-development matrix sites, fawn detections were higher than would be expected at random within 1 day of a coyote detection later in the summer.

\section{4 | Vigilance}

We used 1,526 detection events in vigilance analyses, approximately $46 \%$ of which came from the agriculture-development matrix sites. Adult female deer had the most events $(n=722)$ and adult female deer with fawns had the fewest $(n=138)$. The best model was the
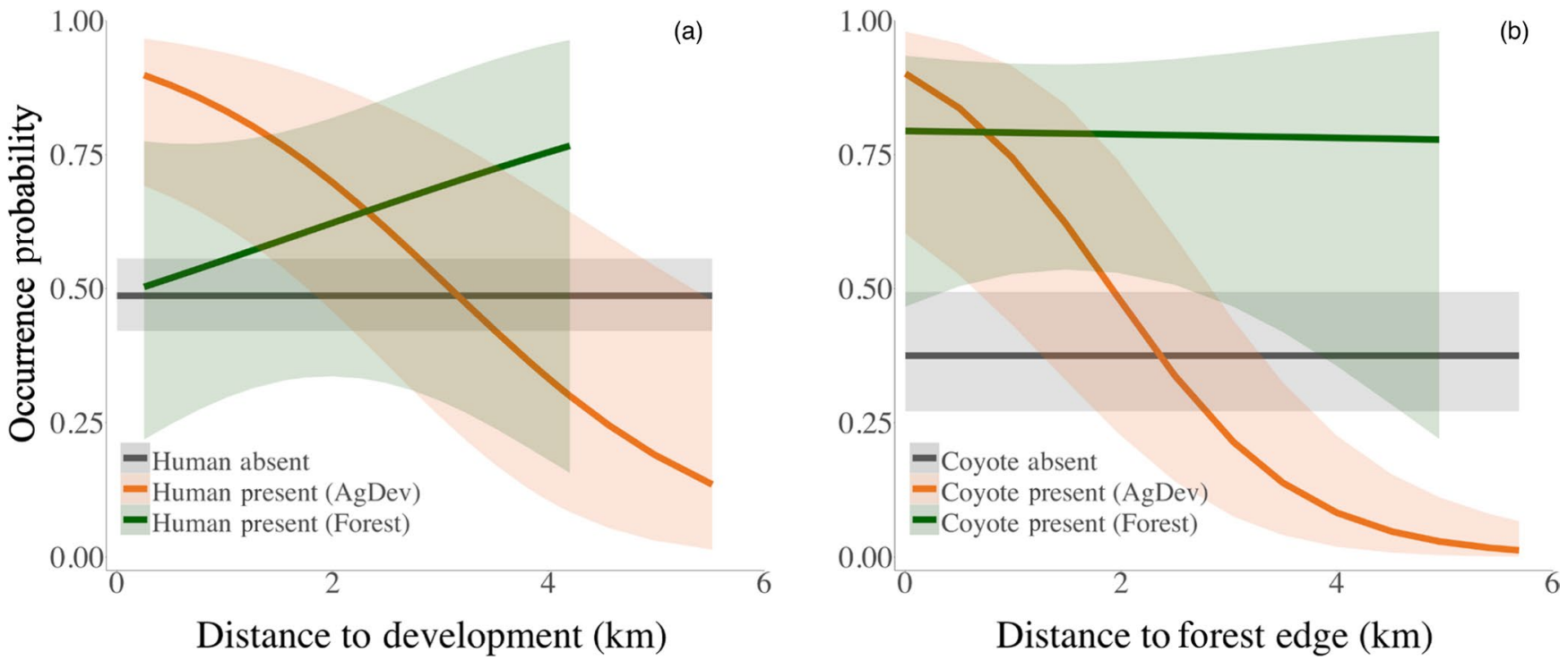

FIGURE 3 Fawn occurrence dependent on human (a) and coyote (b) presence across distance to development (a) and forest edge (b; km). Fawn occurrence becomes unrelated to the anthropogenic disturbance measures when humans and coyotes are absent (gray line). Shaded regions are $95 \%$ confidence intervals 

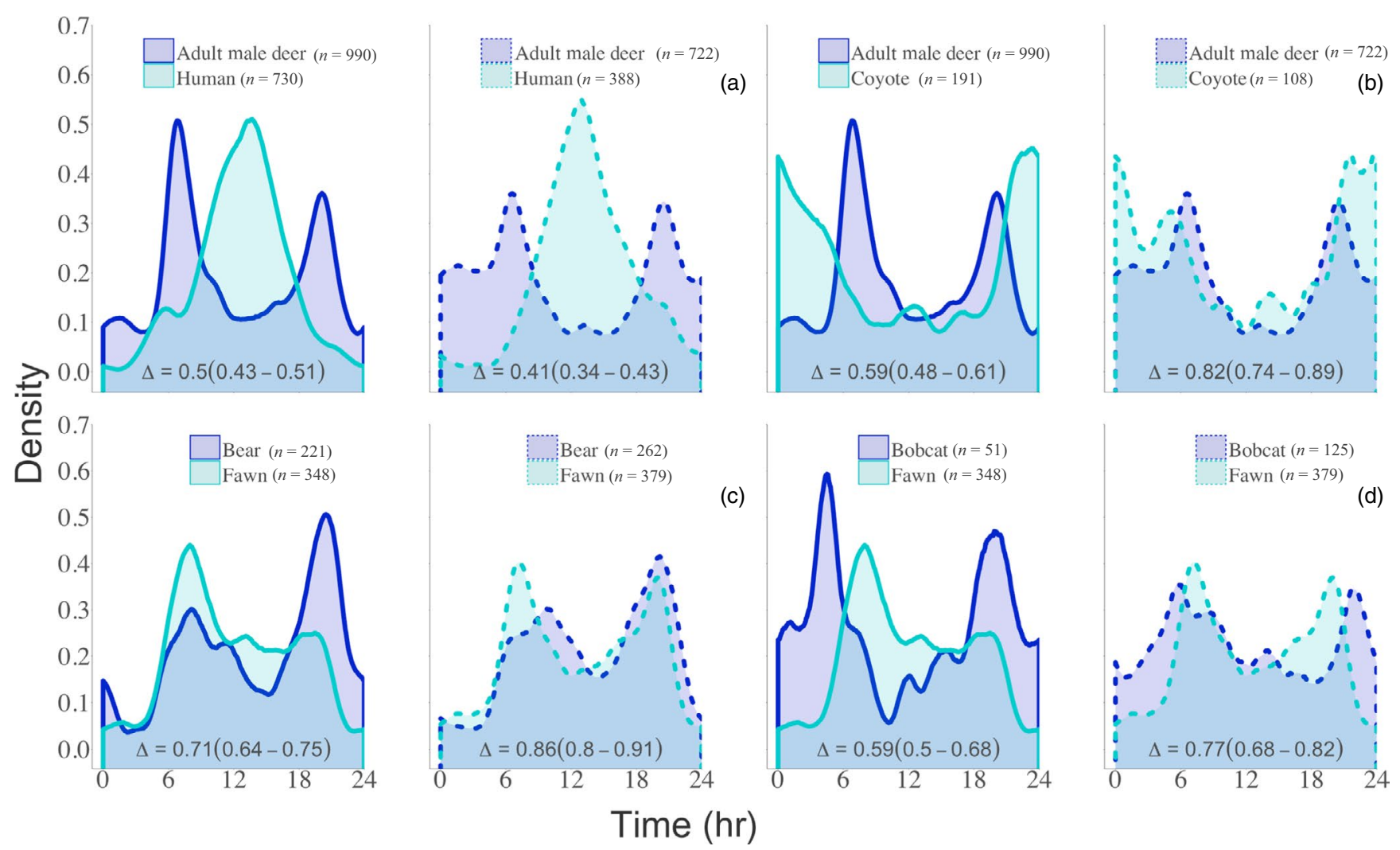

FIGURE 4 Temporal overlap between adult male deer and humans (a) and coyotes (b) and between fawns and bears (c) and bobcats (d). Solid and dashed lines indicate activity patterns at forest matrix site and agriculture-development matrix sites, respectively

FIGURE 5 Coyote-fawn temporal overlap in agriculture-development matrix sites before (a) and after (b) July 26th

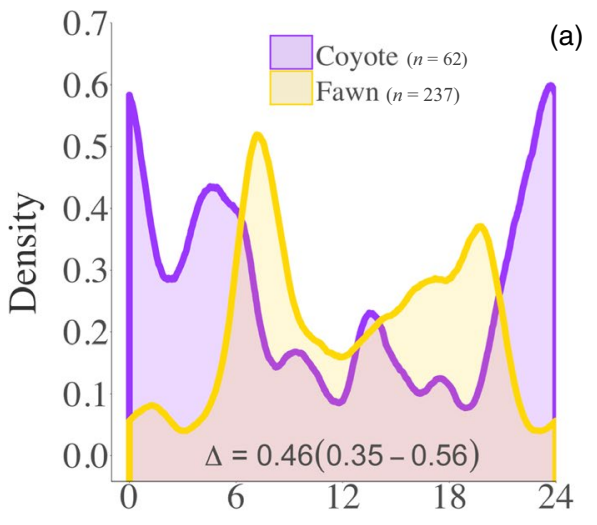

(a)

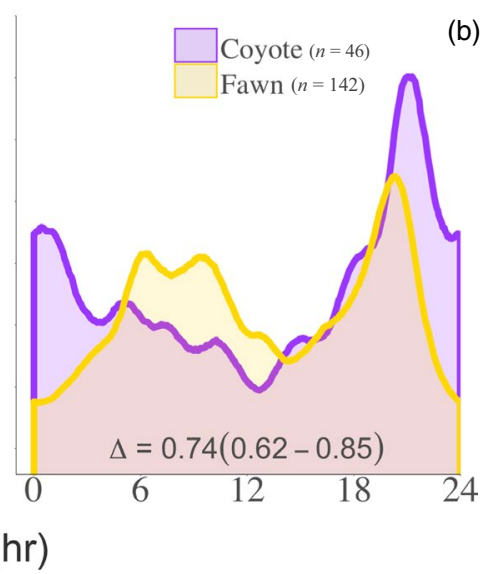

full model where vigilance was related to the matrix type, sex-age class, group size, the time of day, predator relative abundance, distance to forest edge and the survey day, with an interactive effect of matrix type on all covariates except for survey day, which had an interactive effect of matrix type and sex-age class (M11; see Table 3 and Appendix S8).

Overall, deer vigilance tended to depend on matrix type. For example, deer vigilance was higher closer to forest edges, but only in agriculture-development matrix sites (Figure 6a). Deer vigilance was higher during the day (approximately 6:00-18:00) in agriculturedevelopment matrix sites and higher at night (around 18:00-24:00) in the forest matrix sites (Figure 6b). Deer vigilance was positively related to predator relative abundance in the forest matrix site, whereas this relationship was more variable in the agriculturedevelopment matrix sites (Figure 6c). Finally, the vigilance of all sexage classes decreased throughout the summer (Figure 7a,b).

\section{4 | DISCUSSION}

We show that in a human-dominated landscapes, spatial, temporal and spatiotemporal co-occurrence of bears, coyotes, bobcats, adult 


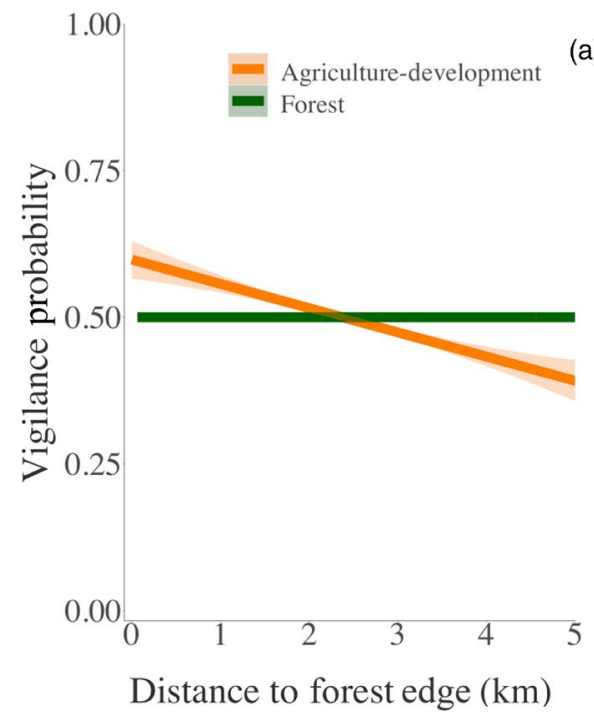

(a)

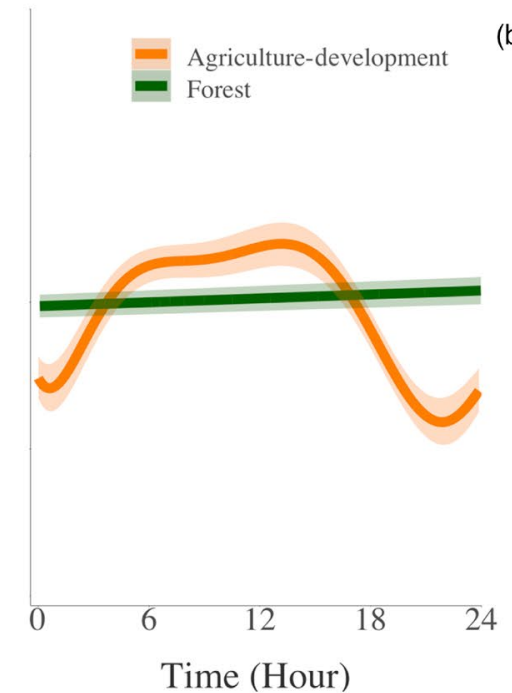

(b)

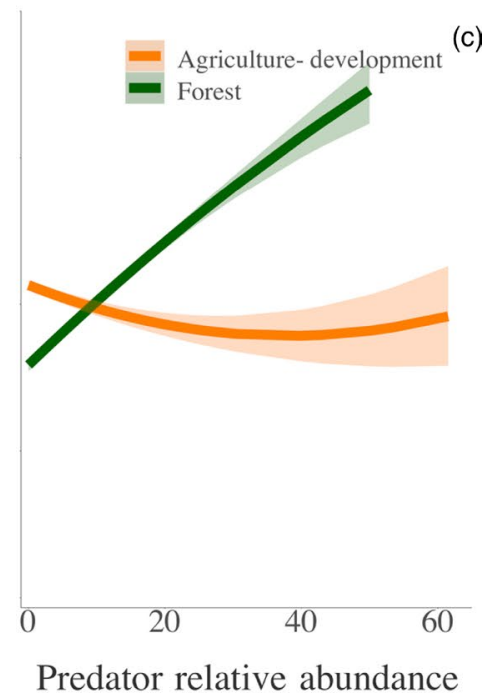

FIGURE 6 Deer vigilance probability and how it relates to distance to forest edge ( $\mathrm{km}$; a), time of day (b), predator relative abundance (c) at the agriculture-development matrix and forest matrix sites. Shaded regions are $95 \%$ confidence intervals

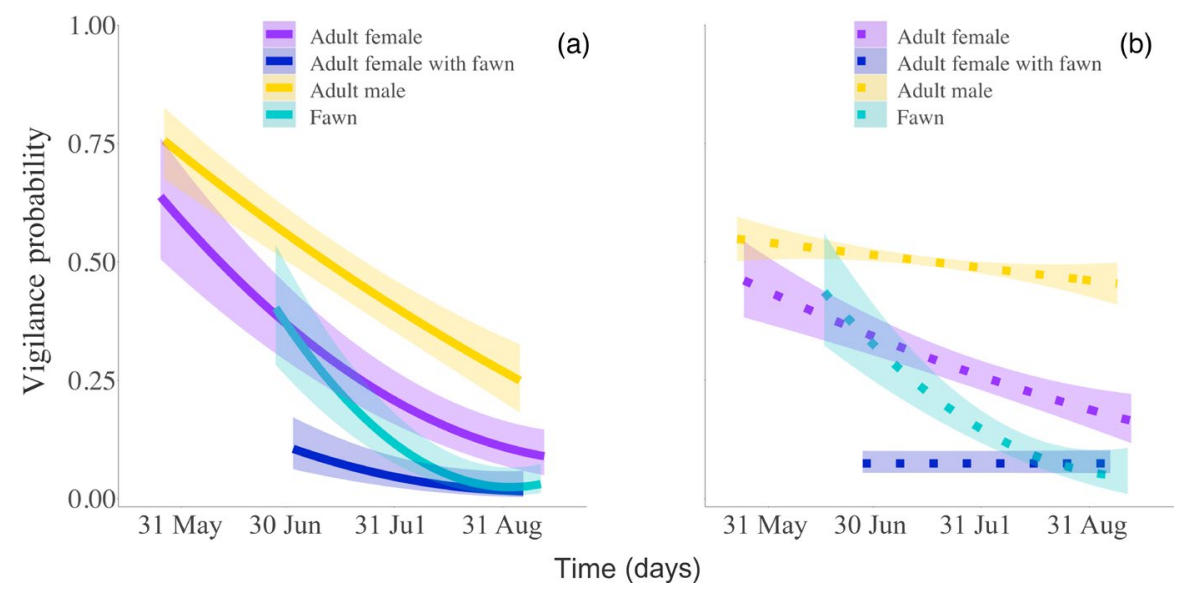

FIGURE 7 Deer vigilance probability and how it relates to survey day at the forest matrix (a) and agriculturedevelopment matrix (b) sites. Shaded regions are $95 \%$ confidence intervals male deer and fawns across multiple scales changed in nature, with anthropogenically disturbed habitat often related to increased spatiotemporal overlap among species. Our results add to the growing body of work that suggest that as human presence increases, we reduce available niche space for wildlife, causing what can be seen as 'neutral' or 'positive' spatiotemporal associations among species (Bonnot et al., 2020; Haswell et al., 2020; Parsons et al., 2019; Smith et al., 2018; Wang et al., 2015). This reduction in available niche space and increase in spatiotemporal overlap among predators, and predators and prey, has important implications for interspecific interactions like predation and competition.

As human-predator interactions can strongly influence predatorprey interactions (Bonnot et al., 2020; Guiden et al., 2019; Smith et al., 2017), we sought to determine whether humans influenced antipredator behaviour in bears, coyotes and bobcats. The positive spatiotemporal association between bears and humans in the forest matrix site, because the human detections in the forest matrix site tended to be motor vehicles on roads rather than humans, might be better explained by bear use of roadsides. Other studies have shown that, while bears generally avoid roads, they might use them as travel corridors (Hiller et al., 2015). The spatial overlap between coyotes and humans is also likely an artefact of habitat selection; human occurrence was higher closer to forest edge, a habitat that coyotes prefer (Kays et al., 2008). When human-coyote habitat use was similar, coyotes spatiotemporally avoided humans. However, when humancoyote habitat use diverged, human-coyote spatiotemporal overlap increased, suggesting a shift in avoidance strategy. Coyotes, while able to live in and use resources in urban areas, tend to avoid human contact (Dodge \& Kashian, 2013; Magle et al., 2014).

As predator-predator interactions can also strongly influence predator-prey interactions (Leblond et al., 2016; Palacios et al., 2016, 2018), we also characterized interactions between the three natural predators. Coyote and bobcat spatial overlap with bears might be due to habitat variables we did not measure. The bobcat spatiotemporal avoidance of coyotes was expected due to the common negative interactions between the two species (Fedriani et al., 2000; 
Litavitis \& Harrison, 1989; Thornton et al., 2004). However, all predator-predator spatiotemporal associations became neutral in the agriculture-development matrix sites. Lewis et al. (2015) found a similar result in short-term spatiotemporal interactions between bobcats and pumas Puma concolor. The shift of spatiotemporal associations, positive or negative, to neutral in the more disturbed sites might be an effect of the reduced habitat available to species in anthropogenically disturbed areas, making spatial avoidance difficult even at the temporal scales we measured.

Despite some instances of ungulates using human presence as a shield from predation for their young (Berger, 2007), our results suggest that fawn spatial distribution was largely driven by habitat. The nature of fawn-human spatial overlap was influenced by distance to developed open space, which might be due to its relatively high correlation with distance to forest edge $(|r|>0.66$; within the threshold for our covariate selection). Based on this, fawn-human spatial overlap in the agriculture-development matrix sites is likely due to habitat preference, as opposed to fawns and their dams using humans as a shield from predation. Fawn temporal overlap with humans was similar across all sites, indicating no increase in temporal avoidance to make up for increased spatial overlap. The positive spatial overlap between fawns and humans in the forest matrix site might be better explained by deer use of roadsides (Duquette et al., 2014). Fawns in the forest matrix site spatiotemporally avoided 'humans' (i.e. motor vehicles on roads) after July 26 , possibly due to a change in habitat use away from roadsides.

In the agriculture-development matrix sites, fawns seemed to use a mixture of strategies to avoid overlapping with natural predators. The only natural predator fawns spatially co-occurred with was coyotes; fawns particularly overlapped in space with coyotes closer to forest edges, as would be expected based on both species' preferences for forest edges (Duquette et al., 2014; Kays et al., 2008). It is possible that fawns increased temporal overlap with bears and bobcats, which were detected less often closer to the forest edges compared to humans, to avoid overlapping too much with humans temporally. Fawn temporal overlap with coyotes also increased, but only after July 26 . This increase in temporal overlap coincided with spatiotemporal avoidance of the same, suggesting fawns traded temporal avoidance of coyotes, as would be expected with a roaming predator (Schmitz et al., 2017), with finer-scale avoidance of the same.

Fawn antipredator behaviour in the forest matrix site showed more use of spatiotemporal avoidance. Fawns still positively cooccurred with humans and coyotes but had higher occurrence closer to development within the public forest. Development within the public forest was mainly roads, and the core had higher rates of within-boundary early successional habitat, which is preferred by deer (Smith, 1991). Fawn temporal overlap with bears and bobcats was less than in the agriculture-development matrix sites, due to fawns having largely diurnal activity with a peak at dawn. While fawn temporal and spatial overlap did not change over the summer, fawn spatiotemporal co-occurrence did. Fawn spatiotemporal avoidance of bobcats increased as the summer went on and at all sites, fawn vigilance decreased throughout the summer, suggesting that, fawns shifted their antipredator behaviour from vigilance and some sort of spatial or temporal avoidance to finer-scale spatiotemporal avoidance.

Although fawns used a combination of spatiotemporal avoidance and vigilance to avoid predation, in their attempt to avoid one predator, they might have made themselves vulnerable to another (Leblond et al., 2016). Fawns spatially avoiding an ambush predator like bobcats on a fine temporal scale would be more efficient than avoiding them completely or shifting their activity patterns and subsequently increasing their temporal overlap with other predators (Schmitz et al., 2017). However, fawns only avoided bobcats at this fine scale in the forest matrix site; they did not avoid them in the agriculture-development matrix sites, possibly due to lower occurrence of bobcats in these sites (Murphy, 2021). Despite this lower occurrence, bobcats were the most common cause of predationrelated death for fawns in the agriculture-development matrix sites (Gingery et al., 2018). Simultaneously, fawns spatiotemporally avoided coyotes in the agriculture-development matrix sites, particularly later in the summer. Coyotes, unlike bobcats, had similar occurrence across the public forest sites (Murphy, 2021). It is possible that, in their attempt to avoid the more common predator in the agriculture-development matrix sites (coyotes), fawns put themselves in danger of being preyed upon by the less common bobcats.

In contrast to fawns, adult male deer showed few examples of antipredator behaviour. Adult male deer only showed avoidance of humans, even to the point of increasing temporal overlap with coyotes in the agriculture-development matrix sites. Adult male deer had a positive spatial relationship with humans in the agriculturedevelopment matrix sites, but a negative one in the forest matrix site. The cause of this change is likely due to humans and adult male deer both being attracted to forest edges in the agriculturedevelopment matrix sites but only adult male deer being attracted to the forest core in the forest matrix site, due to deer preferring early-successional forest (Smith, 1991). Based on habitat use similarity, adult male deer avoided humans either spatially at fine temporal scales or by shifting their activity pattern. While adult male deer vigilance also declined through the summer, adult male deer were more vigilant than fawns and dams with fawns at all sites. Other studies have seen adult male deer have higher rates of vigilance than the other age-sex classes (Gulsby et al., 2018), as adult female deer seem to select for resource acquisition over avoiding fawn predators (Duquette et al., 2014). Although hunting season at these sites started after our surveys ended, it is possible that adult male deer still saw humans as predators to be avoided. More research should investigate how hunted ungulates perceive humans as a risk in nonhunting seasons.

Matrix type had a strong influence on the relationship between vigilance and other factors. The increase in deer vigilance closer to forest edges follows increased spatial overlap with humans and coyotes. Deer vigilance seemed to follow predator and human temporal activity intensity, with vigilance clearly increased during the period of 6:00 to 18:00 in the agriculture-development matrix sites, when humans and 
multiple predators were somewhat active. Meanwhile, in the forest matrix site, vigilance was constant throughout the diel cycle, due to daily activity peaks for predators and humans being asynchronous. We conclude that deer were increasing their vigilance in accordance with the times of day that were perceived as most dangerous, possibly with a focus on when humans were active in the human-dominated sites.

We suspect the reason why deer vigilance was so weakly related to predator relative abundance in the agriculture-development matrix sites might be because of a constant high level of perceived risk. According to the risk allocation hypothesis, prey should show more intense antipredator behaviour in cases where high-risk situations are rare than in situations where there is a consistent, prolonged high level of risk (Lima \& Bednekoff, 1999; Sih \& McCarthy, 2002). This result has been seen many times (Mirza et al., 2006; Mitchell et al., 2016; Sih \& McCarthy, 2002), and more recent studies have shown that animals can even learn diel temporal predation risk based on when a predator is active (Bosiger et al., 2012), which would explain the relationships we see with deer vigilance and time of day. A number of studies have also shown that predators and prey perceive humans as a source of risk (Ciuti et al., 2012; Smith et al., 2017), with humans and anthropogenic disturbance reducing animal movement (Tucker et al., 2018), causing trophic cascades (Suraci et al., 2019), increasing predation rates (Smith et al., 2017) and shifting spatiotemporal habitat use of wildlife (Patten \& Burger, 2018). We posit that a consistently high level of perceived risk from humans may be the reason why studies-including ours-fail to detect antipredator and avoidance behaviours, or detect neutral/ positive spatiotemporal associations, between interacting species in anthropogenically disturbed areas.

Our study provides evidence that adult male deer might perceive humans as a predation risk outside of hunting seasons, that increases in anthropogenic disturbance might cause a dulling effect in natural antipredator behaviour and interspecific interactions, and that prey, through avoiding a more common predator (e.g. coyotes), make spatiotemporal choices that increase their risk of being preyed upon by the less common predator (e.g. bobcats). The spatiotemporal interactions among predators, and predators and fawns, often changed based on matrix type, suggesting that even anthropogenic disturbance outside of the boundaries of protected areas might have strong effects on species interactions (Nickel et al., 2020). Finally, not only did these interspecific interactions change based on matrix type, they often presented themselves via different dimensions (e.g. space, time or vigilance) and at different scales (e.g. $12 \mathrm{hr}$ or 8 days). Because changes in the intensity and direction of interspecific interactions, particularly predator-prey interactions, can scale up to affecting ecosystems, incorporating a more realistic system that includes multiple interacting predators and prey and the ubiquitous human footprint provides a more comprehensive picture of interspecific relationships in our changing world.

\section{ACKNOWLEDGEMENTS}

Research was conducted with the funding and support of the Pennsylvania Game Commission and Pennsylvania State University. A. Murphy was supported by the PNC Financial Corporation
Graduate Fellowship, the Penn State Alumni Association Graduate Fellowship, and the Penn State Bunton-Waller Graduate Award. We would like to thank A. Sperfslage and the private landowners who allowed us to survey on their land. We would also like to thank our field technicians E. Carrollo, B. Snavely, T. Vayer and N. Kluge. Any use of trade, firm or product names is for descriptive purposes only and does not imply endorsement by the U.S. Government.

\section{AUTHORS' CONTRIBUTIONS}

All authors provided input into study design, funding and manuscript writing/revision; A.M., D.M. and D.R.D. worked on analyses.

\section{DATA AVAILABILITY STATEMENT}

Data are available from the Dryad Digital Repository https://doi. org/10.5061/dryad.tdz08kq09 (Murphy et al., 2021).

\section{ORCID}

Asia Murphy (iD https://orcid.org/0000-0001-8446-8978

David Miller (iD https://orcid.org/0000-0002-3011-3677

\section{REFERENCES}

Bastille-Rousseau, G., Rayl, N. D., Ellington, E. H., Schaefer, J. A., Peers, M. J. L., Mumma, M. A., Mahoney, S. P., \& Murray, D. L. (2016). Temporal variation in habitat use, co-occurrence, and risk among generalist predators and a shared prey. Canadian Journal of Zoology, 94, 192-198. https://doi.org/10.1139/cjz-2015-0127

Berger, J. (2007). Fear, human shields and the redistribution of prey and predators in protected areas. Biological Letters, 3, 620-623. https:// doi.org/10.1098/rsbl.2007.0415

Bonnot, N. C., Couriot, O., Berger, A., Cagnacci, F., Ciuti, S., De Groeve, J. E., Gehr, B., Heurich, M., Kjellander, P., Kröschel, M., Morellet, N., Sönnichsen, L., \& Hewison, A. J. M. (2020). Fear of the dark? Contrasting impacts of humans versus lynx on diel activity of roe deer across Europe. Journal of Animal Ecology, 89, 132-145. https:// doi.org/10.1111/1365-2656.13161

Bosiger, Y. J., Lonnstedt, O. M., McCormick, M. I., \& Ferrari, M. C. (2012). Learning temporal patterns of risk in a predator-diverse environment. PLoS ONE, 7, e34535. https://doi.org/10.1371/journ al.pone.0034535

Breviglieri, C. P. B., Piccoli, G. C. O., Uieda, W., \& Romero, G. Q. (2013). Predation-risk effects of predator identity on the foraging behaviors of frugivorous bats. Oecologia, 173, 905-912. https://doi. org/10.1007/s00442-013-2677-9

Bridges, A. S., Vaughan, M. R., \& Klenzendorf, S. (2004). Seasonal variation in American black bear Ursus americanus activity patterns: Quantification via remote photography. Wildlife Biology, 10, 277-284.

Burnham, K. P., \& Anderson, D. R. (2002). Model selection and multimodel inference. Springer-Verlag.

Chamberlain, M. J., Conner, L. M., Leopold, B. D., \& Sullivan, K. J. (1998). Diel activity patterns of adult bobcats in central Mississippi. Proceedings of the Annual Conference of the Southeastern Association of Fish and Wildlife Agencies, 52, 191-196.

Cherry, M. J., Morgan, K. E., Rutledge, B. T., Conner, L. M., \& Warren, R. J. (2016). Can coyote predation risk induce reproduction suppression in white-tailed deer? Ecosphere, 7, e01481. https://doi.org/10.1002/ ecs2.1481

Ciuti, S., Northrup, J. M., Muhly, T. B., Simi, S., Musiani, M., Pitt, J. A., $\&$ Boyce, M. S. (2012). Effects of humans on behaviour of wildlife exceed those of natural predators in a landscape of fear. PLoS ONE, 7, e50611. https://doi.org/10.1371/journal.pone.0050611 
Dodge, W. B., \& Kashian, D. M. (2013). Recent distribution of coyotes across an urban landscape in southeastern Michigan. Journal of Fish and Wildlife Management, 4, 377-385. https://doi.org/10.3996/06201 3-JFWM-040

Dorresteijn, I., Schultner, J., Nimmo, D. G., Fischer, J., Hanspach, J., Kuemmerle, T., Kehoe, L., \& Ritchie, E. G. (2015). Incorporating anthropogenic effects into trophic ecology: Predator-prey interactions in a human-dominated landscape. Proceedings of the Royal Society B: Biological Sciences, 282, 20151602. https://doi.org/10.1098/ rspb.2015.1602

Duquette, J. F., Belant, J. L., Svoboda, N. J., Beyer, D. E. Jr, \& Lederle, P. E. (2014). Effects of maternal nutrition, resource use and multipredator risk on neonatal white-tailed deer survival. PLoS ONE, 9, e100841. https://doi.org/10.1371/journal.pone.0100841

Eccard, J. A., Meißner, J. K., Heurich, M., \& Herberstein, M. (2017). European roe deer increase vigilance when faced with immediate predation risk by Eurasian Lynx. Ethology, 123, 30-40. https://doi. org/10.1111/eth.12420

Embar, K., Raveh, A., Hoffmann, I., \& Kotler, B. P. (2014). Predator facilitation or interference: A game of vipers and owls. Oecologia, 174, 1301-1309. https://doi.org/10.1007/s00442-013-2760-2

Fedriani, J. M., Fuller, T. K., Sauvajot, R. M., \& York, E. C. (2000) Competition and intraguild predation among three sympatric carnivores. Oecologia, 125, 258-270. https://doi.org/10.1007/s0044 20000448

Fiske, I., \& Chandler, R. B. (2011). unmarked: An R package for fitting hierarchical models of wildlife occurrence and abundance. Journal of Statistical Software, 43, 1-23.

Frid, A., \& Dill, L. M. (2002). Human-caused disturbance stimuli as a form of predation risk. Conservation Ecology, 6, 11-26. https://doi. org/10.5751/ES-00404-060111

Gingery, T. M., Diefenbach, D. R., Wallingford, B. D., \& Rosenberry, C. S. (2018). Landscape-level patterns in fawn survival across North America. The Journal of Wildlife Management, 82, 1003-1013. https:// doi.org/10.1002/jwmg.21456

Guiden, P. W., Bartel, S. L., Byer, N. W., Shipley, A. A., \& Orrock, J. L. (2019). Predator-prey interactions in the anthropocene: Reconciling multiple aspects of novelty. Trends in Ecology \& Evolution, 34, 616627. https://doi.org/10.1016/j.tree.2019.02.017

Gulsby, W. D., Cherry, M. J., Johnson, J. T., Conner, L. M., \& Miller, K. V. (2018). Behavioral response of white-tailed deer to coyote predation risk. Ecosphere, 9. https://doi.org/10.1002/ecs2.2141

Haswell, P. M., Kusak, J., Jones, K. A., \& Hayward, M. W. (2020). Fear of the dark? A mesopredator mitigates large carnivore risk through nocturnality, but humans moderate the interaction. Behavioral Ecology and Sociobiology, 74, s00265-00020-02831-00262. https://doi. org/10.1007/s00265-020-02831-2

Hiller, T. L., Belant, J. L., Beringer, J., \& Tyre, A. J. (2015). Resource selection by recolonizing American black bears in a fragmented forest landscape. Ursus, 26, 116-128. https://doi.org/10.2192/URSUS-D15-00023.1

Karanth, K. U., Srivathsa, A., Vasudev, D., Puri, M., Parameshwaran, R., \& Kumar, N. S. (2017). Spatio-temporal interactions facilitate large carnivore sympatry across a resource gradient. Proceedings of the Royal Society B: Biological Sciences, 284. https://doi.org/10.1098/ rspb.2016.1860

Kays, R. W., Gompper, M. E., \& Ray, J. C. (2008). Landscape ecology of eastern coyotes based on large-scale estimates of abundance. Ecological Applications, 18, 1014-1027. https://doi.org/10.1890/07-0298.1

Lashley, M. A., Chitwood, M. C., Biggerstaff, M. T., Morina, D. L., Moorman, C. E., \& DePerno, C. S. (2014). White-tailed deer vigilance: The influence of social and environmental factors. PLOS ONE, 9, e90652. https://doi.org/10.1371/journal.pone.0090652

Leblond, M., Dussault, C., Ouellet, J.-P., St-Laurent, M.-H., \& Singh, N. (2016). Caribou avoiding wolves face increased predation by bears - Caught between Scylla and Charybdis. Journal of Applied Ecology, 53, 1078-1087. https://doi.org/10.1111/1365-2664.12658

Lewis, J. S., Bailey, L. L., VandeWoude, S., \& Crooks, K. R. (2015). Interspecific interactions between wild felids vary across scales and levels of urbanization. Ecology and Evolution, 5, 5946-5961. https:// doi.org/10.1002/ece3.1812

Lima, S. L., \& Bednekoff, P. A. (1999). Temporal variation in danger drives antipredator behavior: The predation risk allocation hypothesis. The American Naturalist, 153, 649-659. https://doi.org/10.1086/303202

Linkie, M., \& Ridout, M. S. (2009). Estimating overlap of daily activity patterns from camera trap data. Journal of Agricultural, Biological, and Environmental Statistics, 14, 322-337. https://doi.org/10.1198/ jabes.2009.08038

Litavitis, J. A., \& Harrison, D. J. (1989). Bobcat-coyote niche relationships during a period of coyote population increase. Canadian Journal of Zoology, 67, 1180-1188. https://doi.org/10.1139/z89-170

Little, A. R., Webb, S. L., Demarais, S., Gee, K. L., Riffell, S. K., \& Gaskamp, J. A. (2016). Hunting intensity alters movement behaviour of whitetailed deer. Basic and Applied Ecology, 17, 360-369. https://doi. org/10.1016/j.baae.2015.12.003

Magle, S. B., Simoni, L. S., Lehrer, E. W., \& Brown, J. S. (2014). Urban predator-prey associations: Coyote and deer distributions in the Chicago metropolitan area. Urban Ecosystems, 17, 875-891.

Mirza, R. S., Mathis, A., \& Chivers, D. P. (2006). Does temporal variation in predation risk inlfuence the intensity of antipredator responses? A test of the risk allocation hypothesis. Ethology, 112, 44-51.

Mitchell, M. D., Chivers, D. P., Brown, G. E., \& Ferrari, M. C. O. (2016). Living on the edge: How does environmental risk affect the behavioural and cognitive ecology of prey? Animal Behaviour, 115, 185192. https://doi.org/10.1016/j.anbehav.2016.03.018

Murphy, A. (2021). Examining how spatial-temporal interactions between multiple predators influence the distribution, vigilance, and survival of white-tailed deer (Odocoileus virginianus) fawns. Pennsylvania State University.

Murphy, A., Diefenbach, D. R., Ternent, M., Lovallo, M., \& Miller, D. (2021). Data from: Threading the needle: How humans influence predator-prey spatiotemporal interactions in a multiple-predator system. Dryad Digital Repository, https://doi.org/10.5061/dryad. tdz08kq09

Nickel, B. A., Suraci, J. P., Allen, M. L., \& Wilmers, C. C. (2020). Human presence and human footprint have non-equivalent effects on wildlife spatiotemporal habitat use. Biological Conservation, 241, 108383. https://doi.org/10.1016/j.biocon.2019.108383

Olson, E. R., Van Deelen, T. R., \& Ventura, S. J. (2019). Variation in antipredator behaviors of white-tailed deer (Odocoileus virginianus) in a multi-predator system. Canadian Journal of Zoology, 97, 1030-1041.

Palacios, M. M., Killen, S. S., Nadler, L. E., White, J. R., \& McCormick, M. I. (2016). Top predators negate the effect of mesopredators on prey physiology. Journal of Animal Ecology, 85, 1078-1086. https:// doi.org/10.1111/1365-2656.12523

Palacios, M. M., Malerba, M. E., \& McCormick, M. I. (2018). Multiple predator effects on juvenile prey survival. Oecologia, 188, 417-427. https://doi.org/10.1007/s00442-018-4182-7

Parsons, A. W., Rota, C. T., Forrester, T., Baker-Whatton, M. C., McShea, W. J., Schuttler, S. G., Millspaugh, J. J., \& Kays, R. (2019). Urbanization focuses carnivore activity in remaining natural habitats, increasing species interactions. Journal of Applied Ecology, 56, 1894-1904. https://doi.org/10.1111/1365-2664.13385

Patten, M. A., \& Burger, J. C. (2018). Reserves as double-edged sword: Avoidance behavior in an urban-adjacent wildland. Biological Conservation, 218, 233-239. https://doi.org/10.1016/j. biocon.2017.12.033

Polis, G. A., \& Holt, R. D. (1992). Intraguild predation: The dynamics of complex trophic interactions. Trends in Ecology \& Evolution, 7, 151154. https://doi.org/10.1016/0169-5347(92)90208-S 
Quinn, A. C. D., Williams, D. M., \& Porter, W. F. (2013). Landscape structure influences space use by white-tailed deer. Journal of Mammalogy, 94, 398-407. https://doi.org/10.1644/11-MAMM-A-221.1

$R$ Core Team. (2020). R: A language and environment for statistical computing. R Foundation for Statistical Computing.

Rayl, N. D., Bastille-Rousseau, G., Organ, J. F., Mumma, M. A., Mahoney, S. P., Soulliere, C. E., Lewis, K. P., Otto, R. D., Murray, D. L., Waits, L. P., \& Fuller, T. K. (2018). Spatiotemporal heterogeneity in prey abundance and vulnerability shapes the foraging tactics of an omnivore. Journal of Animal Ecology, 87, 874-887. https://doi.org/10.1111/1365-2656.12810

Rota, C. T., Ferreira, M. A. R., Kays, R. W., Forrester, T. D., Kalies, E. L., McShea, W. J., Parsons, A. W., \& Millspaugh, J. J. (2016). A multispecies occupancy model for two or more interacting species. Methods in Ecology and Evolution, 7, 1164-1173. https://doi. org/10.1111/2041-210X.12587

Rowcliffe, M. (2021). activity: Animal Activity Statistics. R package version 1.3.1. https://CRAN.R-project.org/package=activity

Schmitz, O. J., Miller, J. R. B., Trainor, A. M., \& Abrahms, B. (2017). Toward a community ecology of landscapes: Predicting multiple predatorprey interactions across geographic space. Ecology, 98, 2281-2292. https://doi.org/10.1002/ecy.1916

Schuttler, S. G., Parsons, A. W., Forrester, T. D., Baker, M. C., McShea, W. J., Costello, R., \& Kays, R. (2017). Deer on the lookout: How hunting, hiking and coyotes affect white-tailed deer vigilance. Journal of Zoology, 301, 320-327. https://doi.org/10.1111/jzo.12416

Shamoon, H., Maor, R., Saltz, D., \& Dayan, T. (2018). Increased mammal nocturnality in agricultural landscapes results in fragmentation due to cascading effects. Biological Conservation, 226, 32-41. https://doi. org/10.1016/j.biocon.2018.07.028

Sih, A., \& McCarthy, T. M. (2002). Prey responses to pulses of risk and safety: Testing the risk allocation hypothesis. Animal Behaviour, 63 , 437-443. https://doi.org/10.1006/anbe.2001.1921

Smith, J. A., Suraci, J. P., Clinchy, M., Crawford, A., Roberts, D., Zanette, L. Y., \& Wilmers, C. C. (2017). Fear of the human 'super predator' reduces feeding time in large carnivores. Proceedings of the Royal Society B: Biological Sciences, 284, 20170433. https://doi.org/10.1098/ rspb.2017.0433

Smith, J. A., Thomas, A. C., Levi, T., Wang, Y., \& Wilmers, C. C. (2018). Human activity reduces niche partitioning among three widespread mesocarnivores. Oikos, 127, 890-901. https://doi.org/10.1111/oik. 04592

Smith, W. P. (1991). Odocoileus virginianus. Mammalian Species, 1-13. https://doi.org/10.2307/3504281

Stillfried, M., Belant, J. L., Svoboda, N. J., Beyer, D. E., \& Kramer-Schadt, S. (2015). When top predators become prey: Black bears alter movement behaviour in response to hunting pressure. Behavioural Processes, 120, 30-39. https://doi.org/10.1016/j.beproc.2015.08.003

Suraci, J. P., Clinchy, M., Zanette, L. Y., \& Wilmers, C. C. (2019). Fear of humans as apex predators has landscape-scale impacts from mountain lions to mice. Ecology Letters, 22, 1578-1586. https://doi. org/10.1111/ele.13344

Thornton, D. H., Sunquist, M. E., \& Main, M. B. (2004). Ecological separation within newly sympatric populations of coyotes and bobcats in south-central Florida. Journal of Mammalogy, 85, 973-982. https:// doi.org/10.1644/BEH-020

Tolon, V., Dray, S., Loison, A., Zeileis, A., Fischer, C., \& Baubet, E. (2009). Responding to spatial and temporal variations in predation risk: Space use of a game species in a changing landscape of fear. Canadian Journal of Zoology, 87, 1129-1137. https://doi.org/10.1139/Z09-101
Tucker, M. A., Böhning-Gaese, K., Fagan, W. F., Fryxell, J. M., Van Moorter, B., Alberts, S. C., Ali, A. H., Allen, A. M., Attias, N., Avgar, T., Bartlam-Brooks, H., Bayarbaatar, B., Belant, J. L., Bertassoni, A., Beyer, D., Bidner, L., van Beest, F. M., Blake, S., Blaum, N., ... Mueller, T. (2018). Moving in the Anthropocene: Global reductions in terrestrial mammalian movements. Science, 359, 466-469. https://doi. org/10.1126/science.aam9712

USGS. (2019). NLCD 2016 Land cover conterminous United States. U.S.G. Survey (Ed.). U.S. Geological Survey.

Valeix, M., Loveridge, A. J., Chamaillé-Jammes, S., Davidson, Z., Murindagomo, F., Fritz, H., \& MacDonald, D. W. (2009). Behavioral adjustments of African herbivores to predation risk by lions: Spatiotemporal variations influence habitat use. Ecology, 90, 22-30. https://doi.org/10.1890/08-0606.1

Vazquez, C., Rowcliffe, J. M., Spoelstra, K., Jansen, P. A., \& Ellison, A. (2019). Comparing diel activity patterns of wildlife across latitudes and seasons: Time transformations using day length. Methods in Ecology and Evolution, 10, 2057-2066. https://doi.org/10.1111/ 2041-210X.13290

Vreeland, J. K., Diefenbach, D. R., \& Wallingford, B. D. (2004). Survival rates, mortality causes, and habitats of Pennsylvania white-tailed deer fawns. Wildlife Society Bulletin, 32, 542-553. https://doi. org/10.2193/0091-7648(2004)32[542:SRMCAH]2.0.CO;2

Wallingford, B. D., Diefenbach, D. R., Long, E. S., Rosenberry, C. S., \& Alt, G. L. (2017). Biological and social outcomes of antler point restriction harvest regulations for white-tailed deer. Wildlife Monographs, 196, 1-26. https://doi.org/10.1002/wmon.1022

Wang, Y., Allen, M. L., \& Wilmers, C. C. (2015). Mesopredator spatial and temporal responses to large predators and human development in the Santa Cruz Mountains of California. Biological Conservation, 190, 23-33. https://doi.org/10.1016/j.biocon.2015.05.007

Way, J. G., Ortega, I. M., \& Strauss, E. G. (2004). Movement and activity patterns of eastern coyotes in a coastal, suburban environment. Northeastern Naturalist, 11, 237-254. https://doi.org/10.1656/10926194(2004)011[0237:MAAPOE]2.0.CO;2

Wilken, S., Verspagen, J. M. H., Naus-Wiezer, S., Van Donk, E., \& Huisman, J. (2014). Comparison of predator-prey interactions with and without intraguild predation by manipulation of the nitrogen source. Oikos, 123, 423-432. https://doi. org/10.1111/j.1600-0706.2013.00736.x

Wood, S. N. (2011). Fast stable restricted maximum likelihood and marginal likelihood estimation of semiparametric generalized linear models. Journal of the Royal Statistical Society, 73, 3-36. https://doi. org/10.1111/j.1467-9868.2010.00749.x

\section{SUPPORTING INFORMATION}

Additional supporting information may be found online in the Supporting Information section.

How to cite this article: Murphy, A., Diefenbach, D. R., Ternent, M., Lovallo, M., \& Miller, D. (2021). Threading the needle: How humans influence predator-prey spatiotemporal interactions in a multiple-predator system. Journal of Animal Ecology, 90, 2377-2390. https://doi.org/10.1111/1365-2656.13548 